The Spens Committee expressed itself as doubtful whether it would be possible to secure the best men for teaching unless a higher total remuneration was offered.

\section{THE PUBLIC HEALTH SERVICE}

The public health service has been more widely affected by the changes resulting from the National Health Service Act than perhaps the rest of the profession realize. Hospitals have been transferred to the Regional Hospital Boards, and maternity and child welfare services from the relatively large number of we'fare authorities, including non-county boroughs and urban and rural districts, to the local health authorities under the Act-namely, about 150 county borough and county councils. Tuberculosis officers, hitherto employed by local authorities, are now mainly officers of the Regional Boards, though a method of joint appointment whereby they are still employed for part of their time by local health authorities for domiciliary and after-care work is being widely adopted.

Under the pyramidal structure which has always obtained in the public health service the number of chief posts has been relatively small in comparison with the total number of practitioners in the service. The effect of the Act has been to make the number of major posts still smaller, although a number of new types of post are being created. It is too early as yet to say what will be the ultimate shape of the service. Professor J. M. Mackintosh, in last year's Educational Number (Sept. 6, 1947 , p. 368 ), suggested that the loss of hospital services would be an ultimate benefit to the medical officer of health, as it would release him for his more proper duties in the promotion of health, with a return of direct interest in environmental services, especially housing. From the point of view of the medical graduate the public health service at the moment may not appear to offer a very promising career, but it is hoped that forthcoming negotiations on remuneration and conditions of service will result in prospects no worse than those for the general practitioner and the specialist.

The Ministry of Health estimate of the number of practitioners in public health in 1944 gave a total of about 2,000 in whole-time local authority appointments (excluding those in hospitals) in England and Wales. The number is not likely to have altered materially. About 200 whole-time tuberculosis officers have been transferred to the Regional Hospital Boards, but other departments hive increased their strength since the war.

\section{The New Entrant}

The new entrant into public health work usually begins as assistant medical officer, doing maternity and child welfare or school medical work or both. The future tendency will be for such medical officers to specialize more directly either on the obstetrical or child-health side and to have opportunities of keeping up clinical knowledge by interchange arrangements with hospitals or by clinical assistantships. For these appointments the D.P.H. is not essential, and the Society of Medical Officers of Health has suggested that special experience in maternity or children's hospitals and the acquirement of some specialist diploma such as the D.C.H. may in fact be more useful than the D.P.H. itself. The Society, however, considers that a Certificate in Public Health, which can be acquired as the first part in the D.P.H. curriculum, should be regarded as a basic qualification for anyone entering the public health service.

Above assistant medical officer level there are a number of senior posts defined in the Askwith Memorandum as "medical officers in charge of departments," which carry a higher rate of salary. These posts are, or should be, sufficiently well remunerated to make a career for those who do not aspire to the chief administrative posts as M.O.H. or deputy M.O.H. For these two grades the D.P.H. is a statutory necessity, and the course can be taken at two schools in London or at ten centres in the rest of Great Britain. Thus the public health service will still provide an interesting career for a man or woman interested in the preventive side of medicine. in the acquisition of knowledge of factors which affect the health of the people, and in the promotion of positive health.

For the above statement we are indebted to Mr. G. L. C. Elliston, M.A., executive secretary of the Society of Medical Officers of Health.

\section{Correspondence}

\section{Mental Health}

SIR,- One cannot help regretting that the recent International Congress on Mental Health, dominated as it was by the psychologists, could not have been more representative of the other social sciences, particularly education. Criticisms were made of teachers-criticisms which it should be said in all fairness could be made against members of other professions-and there was no one to point out that it is not the teaching profession but the educational system which must be revolutionized. There is, 1 think, little doubt that teachers will remain as they are so long as the educational system remains as it is.

Our upbringing and education, in the home and in the school, can largely obliterate or develop such psychic forces as guil and aggression, which the Congress considered in relation to world peace. If parents had a greater knowledge of their own physical and psychological make-up it would improve their methods of training their children, and if enlightened teaching along these lines were to be continued in the schools during the formative years one cannot help feeling that eventually there would be little need for specialists in psychology. So far as the schools alone are concerned training in human relationships should play a far larger part than it does to-day. Greater freedom of individual expression-an outlet for thought-energy and word-energy-is certainly as important, and far more important for later life, than the outlet for physical energy provided, for instance, by the traditional school games. It would be well to remember that the team spirit is of value only if it is not obliterated by the competitive spirit, with all its potentialities for developing and perpetuating aggression.

In short, there are many ways in which a drastically reformed educational system could contribute to mental health. In this endeavour the aid of psychologists would be invaluable. Until such a project is undertaken, however, there is little that individual teachers can do. Meanwhile one feels that the medical profession, which was prominently represented among the speakers at the Congress, would make a more positive contribution to human progress if it put its own house in order in the first instance. In the light of the general acceptance today of the psychosomatic conception of medicine, the curricula and the whole method of training students in the medical schools are glaringly outmoded and inadequate. They continue to turn out doctors who have not only little knowledge of psychology but a positive antagonism towards it, and who feel that only one part of the individual is important and relevantthe body.

All illnesses, even if they are not technically psychosomatic, certainly include superimposed mental disturbances. If a person is ill he is totally ill, and there must be twofold treatment-for the condition and for the person with the condition. The danger of too narrow specialization-of failure to take the broad view-is always with us. With our present knowledge of the pervasive interaction of body and mind it is imperative that the G.P. should have a reasonable degree of psychological knowledge.

It would be well for members of the medical profession-in particular, the psychologists-to ask themselves where they are going. Do they want to supplant the teachers, politicians, statesmen, and sociologists? Would it not be better for them to concentrate on improving their own service to the individual and, through him, to the community? Meanwhile they should not try to give the lay public the impression that they alone have panaceas for all the world's problems. A profound knowledge of psychology is not restricted to those trained in it, as many classical and contemporary authors have shown. On the other hand, even the most highly trained psychologist might be nonplussed at confronting thirty or forty unruly, perhaps antagonistic, children in a hopelessly inadequate classroom. One cannot end without a word of praise for the excellent way in which the Congress was organized.-I am, etc., 